九州大学学術情報リポジトリ

Kyushu University Institutional Repository

\title{
Accumulation of Digestible Materials with Growth of Forages and Digestion of Forage Dry Matter by in vitro Incubation with Rumen Fluid and Pepsin
}

Shimojo, Masataka

Laboratory of Animal Feed Science, Faculty of Agriculture, Kyushu University

Bungo, Takashi

Laboratory of Animal Feed Science, Faculty of Agriculture, Kyushu University

Imura, Yoshimi

Laboratory of Animal Feed Science, Faculty of Agriculture, Kyushu University

Tobisa, Manabu

Laboratory of Animal Feed Science, Faculty of Agriculture, Kyushu University

他

https://doi.org/10.5109/24283

出版情報：九州大学大学院農学研究院紀要. 43 (3/4)，pp.373-382，1999-02. Kyushu University バージョン：

権利関係 : 


\title{
Accumulation of Digestible Materials with Growth of Forages and Digestion of Forage Dry Matter by in vitro Incubation with Rumen Fluid and Pepsin
}

\author{
Masataka Shimojo, Takashi Bungo, Yoshimi Imura, Manabu Tobisa, \\ Naoki Koga, Tao Shao, Muhammad Yunus, Yutaka Nakano*, \\ Ichiro Goto**, Mitsuhiro Furuse and Yasuhisa Masuda \\ Laboratory of Animal Feed Science, Faculty of Agriculture, \\ Kyushu University, Fukuoka 812-8581, Japan

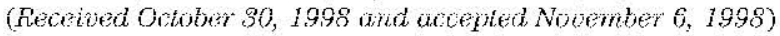

\begin{abstract}
The present study was conducted to suggest an equation to the analysis of forage dry matter digestion by in vitro incubation with rumen fluid and pepsin, and also lo suggest an equation, using digestion rate, 10 the analysis of decreases in dry matter digestibility [DDMD] with growth of forages. Forage digestion characteristics were relative digestion rate of dry matter [RDRW], degradiation rate of lignin [DRL.] and dry matter digestion per unit degradation of lignin [DWTLL]. This method was applied to two tropical forages to evaluate (1) RDRW using DRL and DWDL, and (2) DDMD using RDRW. Accumulation of digestible materials and DDMD using accumulation rate with forage growh (Shimojo et $a l$., 1998a, b, c, 1999) were also taken up and applied to the same tropical forages. Two different-type equations for DDMD suggested, roughly speaking, a sort of relationship between digestion characteristics of forage dry matter in ruminants and accumulation characteristics of digestible matcrials in forages.
\end{abstract}

\section{INTRODUCTION}

Ruminant animals digest forages, but not all the components are digested in the rumen. The amount of materials in forages that are digestible to rumen microbes are, therefore, of importance to the ruminant production from forages (Van Soest, 1982; Minson, 1990). How the digestible materiais accumulate with growth of forages and how forage dry matter is digested by rumen microbes are considered the subject that attracts those people who are interested in forage-ruminant close relationships.

In our recent reports (Shimojo et al., 1998a, b, c, 1999) a simple equation, whose construction was based on the method of forage growth analysis (Hunt, 1990), was suggested to the analysis of the accumulation of digestible materials wilh forage growth and was applied to some tropical forages. In those four papers the amount of digestible materials in forages was determined by in vitro incubation with rumen fluid and pepsin using the method of Minson and McLeod (1972). For evaluating the digestion or degradation characteristics of forages and fibrous feeds in the rumen, there are analytic methods using exponential equations, such as the method of Mertens and Loften (1980) and that of Ørskov (1989). In addition, there might be a possibility of applying growth analysis method, if modified appropriately, to the evaluation of digestion characteristics of forage dry matter. This approach might be expected to give the analytic viewpoint to

\footnotetext{
* Kyushu University Farm, Fukuoka 811-2307

** Liniversity of the Air, Fukuoka Study Center, Fukuoka 812-0016
} 
both the digestion of forage dry matter by rumen fluid and pepsin and the accumulation of digestible materials with growth of forages.

The present study was designed to suggest a simple equation to the analysis of the digestion of forage dry matter by in vilro incubation with rumen fluid and pepsin, followed by suggesting a sort of relationship between digestion characteristics of forage dry matter and accumulation characteristics of digestible materials with growth of forages.

\section{AN EQUATION FOR ANALYZING DIGESTION OF FORAGE DRY MATTER BY IN VITRO INCUBATION}

\section{An equation for analyzing forage dry matter digestion by in vitro incubation with rumen fluid and pepsin}

In the present study the relative digestion rate of forage dry matter [RDRW] by in vitro incubation with rumen fluid and pepsin is taken up. RDRW is suggested as follows:

$\mathrm{RDRW}=\frac{1}{W} \cdot \frac{d W}{d T}$,

where $W=$ forage dry matter weight, $T=$ time of in vitro incubation with rumen fluid followed by pepsin.

The dry matter that is digested by in vitro incubation is regarded as the digestible materials of forages.

Forage dry matter digestion is influenced mainly by lignin that partly protects plant fibers from the attack by rumen microbes and related enzymes (Van Soest, 1982; Minson, 1990; Cheng et al., 1991). It was shown in the long-period in vitro incubation with rumen fluid that the digestion of dry matter advanced with the increase in the degradation of lignin (Goto and Minson, 1977). This was also found in the in vitro incubation with rumen fluid and pepsin, using the method of Minson and McLeod (1972), for forages (Shimojo and Goto, 1984, 1988, 1990b, c) and for cereal straws (Song et al., 1991a, b, c). In those eight reports on the influence of lignin degradation on dry matter digestion, acetyl bromide lignin [ABL] (Morrison, 1972a, b) was used in place of acid detergent lignin [ADL] (Goering and Van Soest, 1970). ADL is widely accepted for the determination of lignin content of forages, and $A B L$ might be considered suitable when the forage digestion is related to the lignin degradation. Also in our previous studies digestibility was related with ABL content for forages (Nakanishi et al., 1985; Shimojo and Goto, 1987, 1990a, b, c) and for cereal straws (Song et al., 1991a, b).

When $\mathrm{ABL}$ degradation is incorporated, equation (1) is rewritten as follows:

$$
\begin{aligned}
\text { RDRW } & =\frac{1}{W} \cdot \frac{d W}{d T} \\
& =\left(\frac{1}{W} \cdot \frac{d(A B L)}{d T}\right) \cdot \frac{d W}{d(A B L)},
\end{aligned}
$$

where $A B L$ denotes its amount, $(1 / W) \cdot(d(A B L) / d T)=$ degradation rate of $A B L$ [DRL] per unit $W,(d W / d(A B L))=$ digestion of $W$ per unit degradation of $A B L$ [DWDL]. 
Thus, RDRW is expressed as the product of DRL and DWDL.

The mean value over the interval $T$ : to $T$, in the in vitro incubation for each of RDRW, DRL and DWDL is approximately as follows:

$\mathrm{RDRW}=\frac{\log _{e} W_{2}-\log _{e} W_{1}}{T_{2}-T_{1}}$,

$\overline{\mathrm{DRL}}=\frac{\log _{e} W_{2}-\log _{e} W_{1}}{W_{2}-W_{1}} \cdot \frac{(A B L)_{2}-(A B L)_{1}}{T_{2}-T_{1}}$,

$\overline{\mathrm{DWDL}}=\frac{W_{2}-W_{1}}{(A B L)_{2}-(A B L)_{1}}$,

where $e=$ the base of natural logarithm.

It is usually recommended that $\overline{\mathrm{RDRW}}, \overline{\mathrm{DRL}}$ and $\overline{\mathrm{DWDL}}$ are determined at intervals of several hours in the incubation.

When the forage is incubated in vitro with rumen fluid for 2 days followed by pepsin for another 2 days (Minson and McLeod, 1972), the amount of digestible materials is described as the difference in $W$ between before and after the 4-day incubation. Thus, if $W$ before the incubation is termed $W_{0}$ and that after the 4-day incubation is termed $W_{4}$ $\left(\dot{W}_{0}>W_{4}\right)$, dry matter digestibility [DMD] is as follows:

$$
\begin{aligned}
\mathrm{DMD} & =-\left(\frac{W_{4}-W_{0}}{W_{0}}\right) \\
& =-\left(\frac{\Delta W}{W_{0}}\right) .
\end{aligned}
$$

Then, the following is given from equation (1),

$$
d W=(\mathrm{RDRW}) \cdot(W) \cdot(d T)
$$

Equation (7) is rewritten as follows when applied to over the 4-day incubation,

$$
\Delta W=4 \cdot(\overline{\operatorname{RDRW}}) \cdot(\bar{W})
$$

Inserting equation (8) into equation (6) gives

$$
\mathrm{DMD}=-4 \cdot\left\{\frac{(\overline{\mathrm{RDRW}}) \cdot(\bar{W})}{W_{0}}\right\} .
$$

As shown in equation (9), the calculation of DMD requires $\overline{R D R W}$ over the 4 -day incubation. Mean value over 4 days does not give detailed descriptions of the digestion process, when compared with $\overline{\mathrm{RDRW}}$ determined at intervals of several hours. It seems, however, that $\overline{R D R W}$ over 4 days might give a broad outline of the digestion rate of forages.

If $\mathrm{DMD}$ of the forage cut at its growth time $t_{1}$ is termed $\mathrm{DMD}_{1}$ and that at $t_{2}$ is termed 
$\mathrm{DMD}_{2}$, then the decrease in DMD [DDMD] with forage growth (from $t_{1}$ to $t_{2}$ ) is described as follows:

$$
\begin{aligned}
\mathrm{DDMD} & =\mathrm{DMD}_{1}-\mathrm{DMD}_{2} \\
& =\left[-4 \cdot\left\{\frac{(\mathrm{RDRW}) \cdot(\bar{W})}{W_{0}}\right\}\right]_{1}-\left[-4 \cdot\left\{\frac{(\mathrm{RDWR}) \cdot(\bar{W})}{W_{0}}\right)\right]_{2} \\
& =-4 \cdot\left[\left\{\frac{(\overline{\mathrm{RDRW}}) \cdot(\bar{W})}{W_{0}}\right\}_{1}-\left\{\frac{(\mathrm{RDRW}) \cdot(\bar{W})}{W_{0}}\right\}_{2}\right] .
\end{aligned}
$$

\section{Applications to two tropical forages}

\section{(A) Forages}

Two tropical forages are Rhodes grass (Chloris gayana Kunth) and Greenleaf desmodium (Desmodium intortum (Mill.) Urb.). Rhodes grass [Rg] and Greenleaf desmodium [Gd] were cut at 35 and 63 days of regrowth with a compound fertilizer $\left(\mathrm{N}: \mathrm{P}_{2} \mathrm{O}_{5}: \mathrm{K}_{2} \mathrm{O}=14: 14: 14 \%\right)$ which had been dressed, immediately after the first cut and discard, at a rate of $1.0 \mathrm{~kg} / \mathrm{a}$ for each element.

(B) Digestion of Rg by in vitro incubation

Digestion characteristics of $\mathrm{Rg}$ before and after in vitro incubation with rumen fluid

\begin{tabular}{|c|c|c|c|c|c|}
\hline \multirow{2}{*}{$\frac{\text { Regrowth: } \ell \text { (days) }}{\text { Incubation: } T \text { (days) }}$} & \multicolumn{2}{|c|}{$35(\mathrm{~A})$} & \multicolumn{2}{|r|}{$63(\mathrm{~B})$} & \multirow[t]{2}{*}{$\mathrm{A} / \mathrm{B}$} \\
\hline & 0 & 4 & 0 & 4 & \\
\hline Forage dry weight: $W\left(\mathrm{~g} / \mathrm{m}^{2}\right)$ & 225.56 & 81.36 & 515.00 & 257.87 & \\
\hline Amount of lignin: $A B L(\mathrm{~g} / \mathrm{m})$ & 20.32 & 11.67 & 61.53 & 41.29 & \\
\hline \multicolumn{6}{|l|}{$\overline{\mathbf{R D R W}}=(\overline{\mathrm{DRL}}) \cdot(\overline{\mathbf{D W D L}})$} \\
\hline$\overline{\mathrm{RDRW}}(\mathrm{g} / \mathrm{g} /$ day $)$ & \multicolumn{2}{|c|}{-0.2549} & \multicolumn{2}{|r|}{-0.1729} & 1.4742 \\
\hline DRI. (g/g/day) & \multicolumn{2}{|c|}{-0.0153} & \multicolumn{2}{|r|}{-0.0136} & 1.1234 \\
\hline$\overline{\text { DWDL }(g / g)}$ & \multicolumn{2}{|c|}{16.6705} & \multicolumn{2}{|r|}{12.7041} & 1.3122 \\
\hline \multicolumn{6}{|l|}{$D M D=-4\left((\overline{R D R W}) \cdot(\bar{W}) W_{0}\right.$} \\
\hline $\mathrm{DMD}(\mathrm{g} / \mathrm{g})$ & \multicolumn{2}{|c|}{0.6393} & \multicolumn{2}{|r|}{0.4993} & 1.2804 \\
\hline $\mathrm{RDRW}(\mathrm{g} / \mathrm{g} / \mathrm{day})$ & \multicolumn{2}{|c|}{-0.2549} & \multicolumn{2}{|r|}{-0.1729} & 1.4742 \\
\hline $\bar{W}(\mathrm{~g})$ & \multicolumn{2}{|c|}{141.41} & \multicolumn{2}{|r|}{371.73} & 0.3804 \\
\hline$W_{0}(\mathrm{~g})$ & \multicolumn{2}{|c|}{225.56} & \multicolumn{2}{|r|}{515.00} & 0.4380 \\
\hline $1 / W_{v}$ & \multicolumn{2}{|c|}{0.0044} & \multicolumn{2}{|r|}{0.0019} & 2.2832 \\
\hline
\end{tabular}

Table 1. Analyses of the digestion of dry matter of Rhodes grass [Rg] by in vitro incubation with rumen fluid of goats for 2 days followed by pepsin for 2 days.

$A B J=$ acetyl bromide lignin, RDRW=relative digestion rate of $W$ by in vitro incubation with rumen fluid and pepsin, DRL=degradation rate of $A B L$ by the incubation, DWDL=digestion of $W$ per unit degradation of $A B L, D M D=$ dry matter digestibility, DDMD=the decrease in DMD during the regrowth; $\bar{W}=$ mean $W$ over the 4-day incubation, $W_{0}=W$ before the incubation. 
of goats and pepsin are shown in Table 1. $\overline{\text { RDRW }}$ was higher at 35 days than at 63 days of regrowth $(-0.2549$ versus -0.1729$)$. This was mainly due to higher $\overline{\mathrm{DWDL}}$ at 35 days (16.6705) compared with that at 63 days (12.7045) of regrowth, with some contribution of slightly higher $\overline{\mathrm{DRL}}(-0.0153$ versus -0.0136$)$.

DMD and its equation's components and DDMD are also shown in Table 1. DMD at 35 days and that at 63 days of regrowth were 0.6393 and 0.4993 , respectively, therefore, DDMD over the interval of 28 days was 0.1400 . The higher DMD at 35 days than at 63 days was mainly due to higher $\overline{\mathrm{RDRW}}(-0.2549$ versus -0.1729$)$, because lower $\bar{W}$ (141.41 versus 371.72 ) seemed to be offset by higher $1 / W_{0}(0.0044$ versus 0.0019$)$.

It was suggested in Rg that the present method accounted analytically for (1) how forage dry matter digestion was influenced by lignin degradation, and also for (2) how the dry matter digestibility and its decreases with forage growth were related to the events in (1).

(C) Digestion of Gd by in vitro incubation

Digestion characteristics of $\mathrm{Gd}$ before and after in vitro incubation with rumen fluid of goats and pepsin are shown in Table 2. There was only a small difference in RDRW between 35 and 63 days of regrowth $(-0.2036$ versus -0.1885$)$. This was due to slightly higher $\overline{\text { DWDL }}$ (13.7289 versus 13.0016), because $\overline{\mathrm{DRL}}$ showed almost the same value $(-0.0148$ versus -0.0145$)$.

DMD and its equation's components and DDMD are also shown in Table 2. DMD at

Table 2. Analyses of the digestion of dry matter of Greenleaf desmodium [Gd] by in vitro incubation with rumen fluid of goats for 2 days followed by pepsin for 2 days.

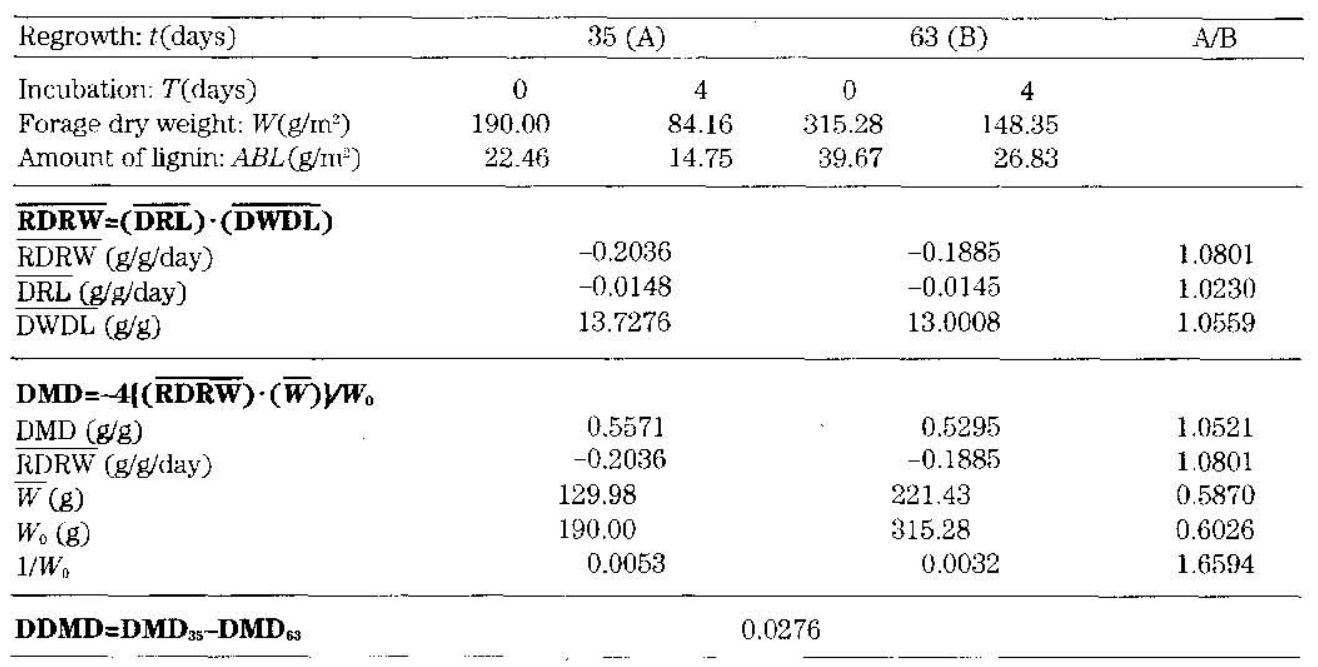

$A B L=$ acetyl bromide lignin, RDRW=relative digestion rate of $W$ by in vitro incubation with rumen fluid and pepsin, $D R L=$ degradation rate of $A B L$ by the incubation, DWDL=digestion of $W$ per unit degradation of $A B L, D M D=$ dry matter digestibility, DDMD=the decrease in DMD during the regrowth, $\bar{W}=$ mean $W$ over the 4 -day incubation, $W_{0}=W$ before the incubation. 
35 days and that at 63 days of regrowth were 0.5571 and 0.5295 , respectively, and DDMD over the interval of 28 days was 0.0276 . The slightly higher DMD at 35 days than at 63 days was mainly due to slightly higher RDRW $(-0.2036$ versus -0.1885$)$, because lower $\bar{W}(129.97$ versus 221.42$)$ seemed to be oflset by higher $1 / W_{0}(0.0053$ versus 0.0032$)$.

It was suggested in Gd that the present method accounted analytically for (1) the influence of lignin degradation on forage dry matter digestion, and for (2) how the dry matter digestibility and its decreases with forage growth were related to the events in (1).

To examine the present method, there is a necessity for applying it to various forages grown under different conditions.

\section{AN EQUATION FOR ANALYZING ACCUMULATION OF DIGESTIBLE MATERIALS WITH GROWTH OF FORAGES}

\section{An equation for analyzing the accumulation of digestible materials with forage growth}

We suggested, in reports (Shimojo et al., 1998a, b, c, 1999), an equation to the analysis of the accumulation of digestible materials with growth of forages. In those four papers the amount of digestible materials was determined by in vitro incubation of forages with rumen fluid of goats and pepsin using the method of Minson and McLeod (1972), namely the method used in the previous section.

The accumulation rate of digestible materials [ARD] per unit dry weight of the forage with its growth is as follows:

$$
\begin{aligned}
\mathrm{ARD} & =\frac{1}{W} \cdot \frac{d D}{d t} \\
& =\left(\frac{D+\frac{d W}{D t}}{W}\right) \cdot\left(\frac{1}{D+\frac{d W}{d t}} \cdot \frac{d D}{d t}\right),
\end{aligned}
$$

where $W=$ forage dry weight, $D=$ dry weight of digestible materials in the forage, $t=$ days of forage growth, $(d W / d t)=$ new photosynthates (expressed in weight, not in rate), $(D+$ $d W / d t)=$ source materials $[S]$ for $D$ accumulation, $(D+d W / d t) / W=$ the ratio of $S$ to $W$ [S ratio], $[[1 /(D+d W / d t)\} \cdot(d D / d t)]=$ accumulation rate of $D$ per unit $S$ [ARDS].

With forage growth dry matter digestibility [DMD] normally decreases even when there occurs the accumulation of $D$. The decrease in dry matter digestibility [DDMD] with forage growth is as follows:

$$
\begin{aligned}
\mathrm{DDMD} & =\frac{D_{1}}{W_{1}}-\frac{D_{2}}{W_{2}} \\
& =\left(1-\frac{W_{1}}{W_{2}}\right) \cdot\left(\frac{D_{1}}{W_{1}}-\frac{\overline{\mathrm{ARD}}}{\overline{\mathrm{RGR}}}\right),
\end{aligned}
$$

where $\overline{\mathrm{ARD}}=$ mean $\mathrm{ARD}$ over the interval $t_{1}$ to $t_{u}, \overline{\mathrm{RGR}}=$ mean relative growth rate [RGR] of the forage over the interval $t_{1}$ to $t_{2},\left(1-W_{1} / W_{2}\right)=$ forage growth index $\left[\mathrm{FG}\right.$ index], $\left\{D_{1} / W\right.$ : 
$-\overline{\mathrm{ARD}} / \overline{\mathrm{RGR}}=\mathrm{an}$ index for the decrease in dry matter partition into digestible materials [DDMPD index].

The mean value over the interval $t_{1}$ to $t_{2}$ for each of $\mathrm{ARD}, \mathrm{S}$ ratio, ARDS and RGR is approximately as follows:

$$
\begin{aligned}
& \mathrm{ARD}=\frac{\log _{2} W_{2}-\log _{e} W_{1}}{W_{2}-W_{1}} \begin{array}{c}
D_{2}-D_{1} \\
t_{2}-t_{1}
\end{array} \\
& \overline{\mathrm{S} \text { ratio }}=\left(\frac{D_{2}-D_{1}}{\log _{0} D_{2}-\log _{e} D_{1}}+\begin{array}{c}
W_{2}-W_{1} \\
t_{2}-t_{1}
\end{array}\right) \cdot \frac{\log _{e} W_{2}-\log _{e} W_{1}}{W_{2}-W_{1}}, \\
& \overline{\mathrm{ARDS}}=\frac{1}{D_{2}-D_{1}}+\frac{W_{2}-W_{1}}{t_{2}-t_{1}} \cdot \frac{D_{2}-D_{1}}{t_{2}-t_{1}}, \\
& \overline{\mathrm{RGR}}=\frac{\log _{e} D_{2}-\log _{e} D_{2}-\log _{e} W_{1}}{t_{2}-t_{1}},
\end{aligned}
$$

where $e=$ the base of natural logarithm.

\section{Applications to the two tropical forages}

\section{(A) Forages}

The two tropical forages, Rhodes grass [Rg] and Greenleaf desmodium [Gd], are the

Table 3. Analyses of the accumulation of digestible materials with growth of Rhodes grass [Rg] and Greenleaf desmodium [Gd].

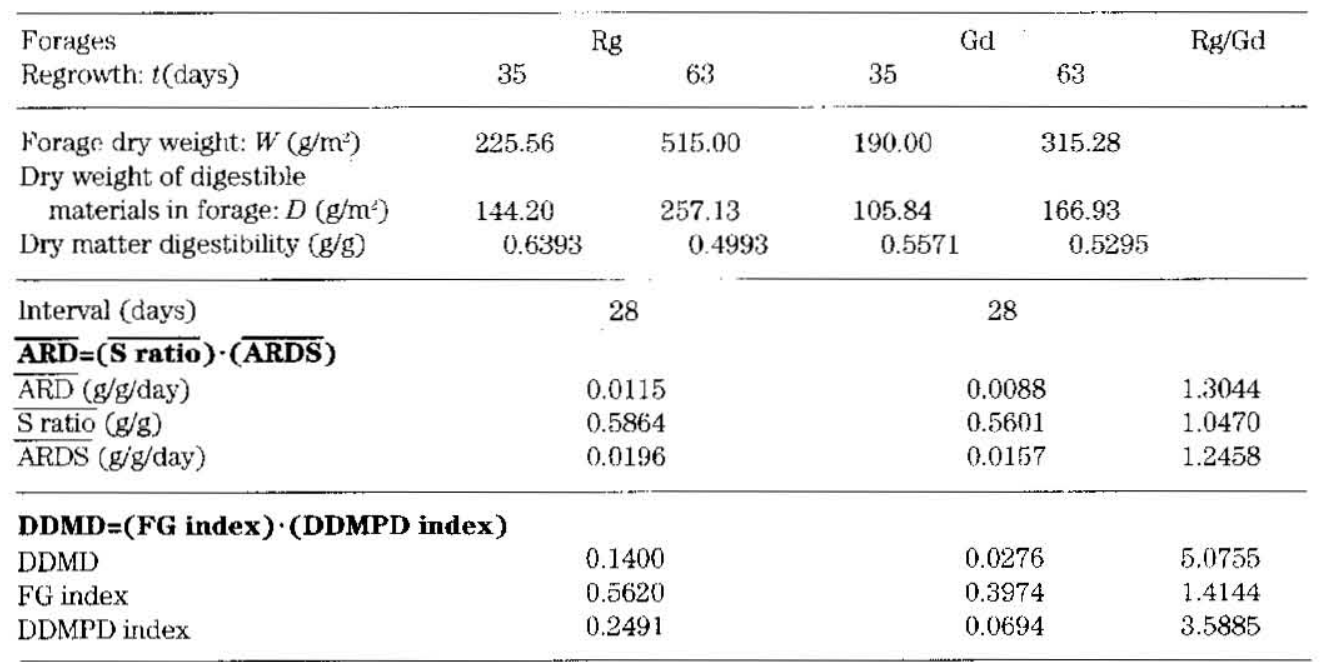

$\mathrm{RGR}=$ forage relative growth rate, $\mathrm{ARD}=$ accumulation rate of $\mathrm{D}$ per unit $W, \mathrm{~S}$ ratio=the ratio of source materials $[S](S=D+d W / d t)$ to $W, \mathrm{ARDS}=$ accumulation rate of $D$ per unit $S, \mathrm{DI}) \mathrm{MD}=1 \mathrm{hle}$ decrease in dry matter digestibility during the regrowth, FG index=forage growth index, DDMPD index=an index for the decrease in dry matter partition into digestible materials. 
same as used in the analysis of digestion characteristics in the previous section.

(B) $\overline{\mathrm{ARD}}$ and DDMD for Rg and those for Gd over the growth of them

Forage characteristics, $\overline{A R D}$ and its components, and DDMD and its equation's components for $\mathrm{Rg}$ and those for $\mathrm{Gd}$ are shown in Table 3. In the present study, comparisons were made between $\mathrm{Rg}$ and $\mathrm{Gd}$. $\overline{\mathrm{ARD}}$ of $\mathrm{Rg}(0.0115)$ was higher than that of Gd (0.0088). This was mainly due to higher ARDS in Rg compared with Gd $(0.0196$ versus 0.0157 ), because $\overline{\mathrm{S} \text { ratio }}$ showed only a small difference between the two forages (0.5864 versus 0.5601$)$.

DDMD was larger in Rg than in Gd (0.1400 versus 0.0276$)$. This was mainly due to higher DDMPD index of $\mathrm{Rg}(0.2491)$ compared with that of Gd (0.0694), with some contribution of $\mathrm{FG}$ index (0.5620 versus 0.3974$)$.

It was suggested that this method accounted analytically for (1) how the digestible materials accumulated with forage growth and (2) how the decrease in dry matter digestibility was related to forage growth and dry matter partition into digestible materials. This was shown in previous reports (Shimojo et al., 1998a, b, c, 1999), but there is a necessity for its further examining using various forages grown under different conditions.

\section{DDMD EQUATION USING RDRW AND THAT USING ARD}

In the present study two different-type equations for describing DDMD were suggested, namely DDMD equation using RDRW [equation (10)] and that using ARD [equation (12)]. Thus, the following relationship is given

$$
-4 \cdot\left\{\left\{\frac{(\overline{\mathrm{RDRW}}) \cdot(\bar{W})}{W_{0}}\right\}_{1}-\left\{\frac{(\overline{\mathrm{RDRW}}) \cdot(\bar{W})}{W_{0}}\right\}_{2}\right]=\left(1-\frac{W_{1}}{W_{2}}\right) \cdot\left\{\frac{D_{1}}{W_{1}}-\frac{\overline{\mathrm{ARD}}}{\overline{\mathrm{RGR}}}\right\} .
$$

The left-hand side of equation (17) accounts for how DDMD is related to $\overline{\mathrm{RDRW}}$ given by the in vitro incubation of forages with rumen fluid and pepsin, and the right-hand side accounts for how DDMD is related to $\overline{\mathrm{ARD}}$ with growth of forages. This suggests, roughly speaking, a sort of relationship between forage digestion characteristics in ruminants and accumulation characteristics of digestible materials in forages through digestibility changes with growth of forages. It also seems that equation (17), as it includes forage $\overline{\mathrm{RGR}}$ in the right-hand side, analyzes forages from the viewpoint of both production and utilization characteristics.

Anyway, the two methods taken up in the present study should be applied to various cases.

\section{Conclusions}

Simple equations were suggested to the analysis of forage digestion by in vitro incubation with rumen fluid and pepsin and to the description of digestibility decreases with forage growth. The digestion characteristics of forage dry matter was related to the degradation characteristics of lignin. Forage dry matter digestion characteristics were 
related with accumulation characteristics of digestible materials in forages through two different-type equations describing digestibility decreases with growth of forages.

\section{ACKNOWLEDGEMENTS}

We wish to thank Mr. Yasukatsu Yano for his skilled technical assistance in the present work.

\section{REFERENCES}

Cheng, K. -J., C. W. Forsberg, H. Minato and J. W.Costerton 1991 Microhial ecology and physiology of feed degradation within the rumen. In "Physiological Aspects of Digestion and Metabolism in Ruminants ", ed. by T. Tsuda et al., Academic Press, Inc., San Diego, pp. 595-624

Goering, H. K. and P. I. Van Soest 1970 Forage fiber analyses. Agriculture Handbook (U.S.D.A.), No. 379: $1-20$

Goto, I. and D. J. Minson 1977 The potential digestibility of leaf and stem fractions of grasses. J. Agric. Sci, Camb., 89: 143-149

Hunt, R. 1990 Basic Growth Aralysis. Unwin Hyman Ltd, London, U. K.

Mertens, D. R. and J. R. Loften 1980 The effect of starch on forage fiber digestion kinetics in vitro. J.Dairy Sci., 63: 1437-1446

Minson, D. J. 1990 Digestible energy of forage. In "Forage in Ruminant Nutrition", Acadcmic Press, Inc., San Diego, pp. 85-149

Minson, D. J. and M. N. McLeod 1972 The in vitro technique: Its modification for estimating digestibility of large numbers of tropical pasture samples. C.S.I.R.O. Div. Trop. Pastures Tech.Pap., No. 8: 1-15

Morrison, I. M. $1972 \mathrm{a}$ A semi-micro method for the determination of lignin and its use in predicting the digestibility of forage crops. J. Sci. Food Agric., 23: $455-463$

Morrison, I. M. $1972 \mathrm{~b}$ Improvements in the acetyl bromide technique to determine lignin and digestibility and its application to legumes. I. Sci. Food $\mathrm{Agric}$, 23: 1463-1469

Nakanishi, Y., M. Shimojo and I. Goto 1985 Effect of growing stages of Rhodes grass on ingestive behaviour of grazing goats. Sci. Bull. Fac. Agr., Kyushu Eniw., 40: 33-38 (in Japanese with English summary)

Orskov, E. R. 1989 Recent advances in cvaluation of roughages as feeds for ruminants. In "Recent Advances in Animal Nutrition in Australia 1989", ed. by D. J. Farrell, Uriversity of New England Printery, Arruidale, pp. 102-108

Shimojo, M. and I. Goto 1984 A study on the relation between disappearance of dry matter and acetyl bromide lignirl of tropical grass. Jpn. J. Zootech Sci., 55: 838-842 (in Japanese with English summary)

Shimojo, M. and I. Goto 1987 A study on the relation between organic matter disappcarance and acetyl bromide lignin of tropical forages. Jpn J. Zootech Sci, 58: $750-753$ (in Japanese with English summary)

Shimojo, M. and I. Goto 1988 A study on the relation between organic matter and acetyl bromide lignin disappearances in tropical legumes. Sci. Bull. Fac. Agr., Kyushu Univ., 42: 153-156 (in Japanese with English summary)

Shimojo, M and I. Goto 1990a Improvement of nutritive value of tropical grasses by physical or chemical treatment. 1. Effect of steam treatment on chemical composition and iry matter digestibility. $J$. Japan. Grassl. Sci, 36: 184-190 (in Japanese with English summary)

Shimojo: M and I. Goto $1990 \mathrm{~b}$ Improvement of rutritive value of tropical grasses by physical or chemical treatment. 2. Effect of wet trealment with sodium hydroxide on chemical composition and dry matter digestibility. J. Japan. Grassl. Sci, 36: 191-196 (in Japanese with English summary)

Shimojo, M and I. Goto $1990 \mathrm{c}$ Improvement of nutritive value of tropical grasses by physical or chemical treatment. 3. Effect of ammonia treatment on chemical composition and dry matter digestibility. $J$. Japan. Grassl. Sci., 36: 197-202 (in Japanese with English summary)

Shimojo, M., T. Bungo, M. Tobisa, Y. Imura, N. Koga, S. Tao, M. Yunus, Z. Yin, Y. Nakano, I. Goto and Y. 
Masuda 1998a Accumulation of digestible materials and decrease in dry matter digestibility in the growth of two tropical grasses. J. Fac. Agr:, Kyushu Linix., 42: 365-372

Shimojo, M., T. Bungo, S. Tao, Y. Imura, M. Tobisa, N. Kuga, M. Yunus, Y. Nakano, I. Goto, M. Furuse and Y. Masuda, $1998 \mathrm{~b}$ Analyses of accumulation of digestible materials and decrease in dry matter digestibility with growth of Rhodes grass. Proc. 8th World Conf Anim. Prod., Scoul, Korea, Vol. II: 516.517

Shimojo, ., T. Bungo, Y. Inura, M. Tobisa, N. Koga, S. Tao, M. Yunus, Y. Nakano, 1. Goto, M. Furuse and Y. Masuda 1998: Accmmilation rate of digestible materials and formation rate of indigestible matcrials in the description of relative growth rate of forages. J. Fac. Agri, Kyushu Lniv., 43: 119-126

Shimojo, M., T. Bungo, Y. Imura, M. Tobisa, N. Koga, T. Shao, M. Yunus, Y. Nakano, 1. Goto, M. Furuse arid Y. Masucia 1999 Two different-type equations of relative growth analysis for both forages and ruminants and deriving of them from a hypothetic equation. \&. Fac. Agr., Kyushu Enin., 43: in press

Song, Y. H., M. Shimojo and I. Goto 1991 a Improvement of nutritive value of rice straw by treatment with armonia and sulphur dioxide. J. Far. Agr., Kyushu Lniv., 36: 143-149

Song, Y. II., M. Shimojo and I. Goto $1991 \mathrm{~b}$ Improvement of nutritive value of barley straw by treatment with ammonia and sulphur dioxide. J. Fac. Agr., Kyushu Lniv., 36: 151-156

Song, Y. H., M. Shimojo and I. Goto 1991e Elfect of sulphur dioxide treatment on the quality of wheat straw pretreated with arumoria. J. Fac. Agr., Kyushu Univ., 36: 157-164

Van Soest, P. J. 1982 Nutritional quality. In "Nutritional Fcology of the Ruminant", Cornell tiniversity Press, New York, pp. 23-74 